\title{
Comunicação
}

[Comunication]

\section{População de protozoários ruminais em novilhos zebuínos alimentados com ou sem volumoso}

[Population of Protozoa in zebu steers fed with or without bulk]

\author{
A.C.A. Nigri' ${ }^{1}$, I.C.O. Ribeiro ${ }^{1}$, E.A. Vieira ${ }^{1}$, M.L.F. Silva ${ }^{2}$, G.F Virgínio-Júnior ${ }^{1}$, F.O. Abrão ${ }^{3}$, \\ L.C. Geraseev ${ }^{1}$, E.R. Duarte ${ }^{*}$ \\ Instituto de Ciências Agrárias - UFMG -Montes Claros, MG \\ ${ }^{2}$ Universidade Estadual do Sudoeste da Bahia - Uesb - Itapetinga, BA \\ ${ }^{3}$ Instituto Federal Goiano - IF Goiano - Ceres, GO
}

Em regiões de clima semiárido, a produção de pastagens de boa qualidade é comprometida durante longo período de estiagem. A redução da digestibilidade dos tecidos vegetais ocorre devido ao processo fisiológico de lignificação da parede celular (Carvalho e Pires, 2008).Nesse período, a ingestão de matéria seca diminui significativamente, resultando em perda de peso corporal. Em razão da redução no desempenho animal, a suplementação da dieta torna-se relevante,visando atender às necessidades dos animais (Zervoudakiset al.,2002).

O sistema de confinamento sem volumoso, só com milho grão inteiro e pellet proteico, pode viabilizar a engorda de bovinos, com ganhos em torno de $1,5 \mathrm{~kg} / \mathrm{cab} / \mathrm{dia}$, e tem sido utilizado em diferentes sistemas de produção bovina. Entretanto, devido ao risco de acidose e de outras alterações metabólicas, essas dietas podem propiciar variações significativas nas populações de microrganismos ruminais (Gorocica-Buenfil; Loerch, 2005; Abrão et al., 2015).

O rúmen alberga complexa população microbiana, como protozoários, fungos e bactérias, que estabelecem interações positivas e negativas, responsáveis pela fermentação do alimento e pela produção de ácidos graxos de cadeia curta. Os protozoários foram os primeiros microrganismos a serem descritos nesse ambiente e podem representar $2 \%$ de peso do conteúdo ruminal, $40 \%$ do nitrogênio total e $60 \%$ do produto final da fermentação (Kamra, 2005).

Estudos têm registrado importante participação dos protozoários na digestão e no equilíbrio do ecossistema ruminal, bem como na saúde dos ruminantes (Kamra, 2005, Takenaka et al., 2004). Entretanto, pouco ainda é conhecido sobre a ecologia e a importância desses microrganismos para animais submetidos à dietas desafiadoras, como as pastagens de baixo valor nutricional e frequentemente lignificadas, e a dietas sem volumoso, em confinamento, com milho grão inteiro. A análise do perfil da população de ciliados pode retratar as condições do ecossistema ruminal (Dirksen, 1993). Dessa forma, nesta pesquisa, avaliaram-se a concentração e o perfil da população autóctone de protozoários presentes no rúmen de novilhos de corte, alimentados com ou sem volumoso.

A amostragem deste estudo foi constituída por 50 novilhos Nelore mestiços, com 30 a 40 meses de idade, provenientes de propriedades do norte do estado de Minas Gerais. A região do presente estudo localiza-se aproximadamente a $16^{\circ} 51^{\prime}$ de latitude e $44^{\circ} 55^{\prime}$ de longitude, apresenta clima tropical (AS) com temperatura média anual de $24,2^{\circ} \mathrm{C}$, clima quente e seco e período de estiagem de abril a outubro (Alvares et al., 2014).

Recebido em 1 de dezembro de 2016

Aceito em 3 de dezembro de 2016

*Autor para correspondência (corresponding author)

E-mail: duartevet@hotmail.com 
Foram avaliados dois grupos de animais, sendo o primeiro constituído por 30 animais criados e terminados em sistema extensivo em Brachiaria spp. com suplementação mineral (Tab. 1). As coletas do fluido ruminal nesses animais ocorreram entre o final de março e o início de novembro, correspondendo ao período seco da região, quando as pastagens encontravam-se mais lignificadas.

No segundo grupo, foram avaliados 20 novilhos confinados durante 71 dias, sendo 11 dias para adaptação e 60 dias para período experimental.
Durante o período da pesquisa, receberam somente concentrado peletizado proteico, vitamínico e mineral ( $15 \%$ da dieta) e grãos de milho inteiros ( $85 \%$ da dieta), com dois tratos diários. O consumo médio por animal/dia foi de $8,58 \mathrm{~kg}$. O produto comercial, na forma de pellets, era constituído por fosfato bicálcico, farelo de algodão, carbonato de cálcio, casca de soja moída, farelo de soja, sulfato de cálcio, ureia pecuária e premix mineral vitamínico (Tab. 1). A amostragem desse grupo de novilhos foi realizada no mês de maio, período de abate dos animais.

Tabela 1. Composição bromatológica de forragens do gênero Brachiaria provenientes de propriedades rurais do norte de Minas Gerais, fornecidas aos animais deste experimento, e da dieta sem volumoso, fornecida para os novilhos durante 71 dias de confinamento

\begin{tabular}{lccc}
\hline \multicolumn{1}{c}{ Parâmetros } & $\begin{array}{c}\text { Pastagem } \\
\text { Montes Claros }\end{array}$ & $\begin{array}{c}\text { Pastagem } \\
\text { Coração de Jesus }\end{array}$ & Dieta sem volumoso* \\
\hline MS (\% na MN) & 67,75 & 54,65 & 90,23 \\
FDN (\% na MS) & 74,42 & 80,18 & 20,04 \\
FDA (\% na MS) & 39,20 & 45,93 & 6,22 \\
Lignina (\% na MS) & 10,37 & 9,01 & - \\
PB (\% na MS) & 2,61 & 5,51 & 17,85 \\
EE (\% na MS) & 1,71 & 1,17 & 3,61 \\
Minerais (\% na MS) & 8,68 & 5,70 & 8,00 \\
\hline
\end{tabular}

Nota: MS: matéria seca; MN: matéria natural; FDN: fibra em detergente neutro; FDA: fibra em detergente ácido; PB: proteína bruta; EE: extrato etéreo.*Dieta completa com milho grão e concentrado peletizado e sem volumoso.

Para ambos os grupos, realizou-se jejum de 12 a 18 horas, abate e coleta do fluido do rúmen por incisão do saco ventral do rúmen, com a prévia concussão cerebral e sangria em abatedouro com inspeção municipal ou federal. Os procedimentos adotados com os animais foram submetidos e aprovados pelo Comitê de Ética em Experimentação Animal da UFMG, protocolo $\mathrm{n}^{\circ}$ $156 / 05$.

Foram coletados aproximadamente $15 \mathrm{~mL}$ do fluido ruminal, com o auxílio de pipetas estéreis invertidas. As amostras foram transportadas em caixas isotérmicas a $4^{\circ} \mathrm{C}$ e armazenadas até uma hora, em tubos de ensaio. Posteriormente, no laboratório, amostras de $1 \mathrm{~mL}$ desses fluidos foram diluídas em $9 \mathrm{~mL}$ de solução de formaldeído a $10 \%$ para conservação das estruturas morfológicas dos protozoários (Dehority, 1993). Para a quantificação dos protozoários, foram realizadas diluições decimais em tubos contendo $9 \mathrm{~mL}$ de solução salina,para contagem de protozoários pequenos, médios e grandes, em câmara de Sedgewick Rafter, em microscópio óptico (Dehority, 1993; Dirksen, 1993).

Para identificação dos protozoários, foram utilizadas alíquotas das diluições $10^{-1}$ ou $10^{-2}$, juntamente com uma gota de lugol em lâminas de microscopia, para visualização em microscópio óptico das microestruturas dos protozoários. Utilizou-se objetiva de 40x, e aproximadamente 100 protozoários por animal foram classificados de acordo com a chave descrita em Dehority (1993). As características físico-químicas dos fluidos ruminais foram avaliadas, e o pH estimado, utilizando-se um potenciômetro digital (Dirksen, 1993).

O delineamento do experimento foi inteiramente ao acaso. Após análise exploratória, as concentrações obtidas foram transformadas em $\log _{10}(\mathrm{x}+10)$ e comparadas utilizando-se teste de $t$ student. Para análise das ocorrências dos gêneros, foi utilizado o teste do qui-quadrado. Os dados foram processados no sistema para análises estatísticas, SAEG, considerando-se o nível de significância de $5 \%$. 
As populações de protozoários pequenos, médios e grandes em novilhos alimentados sem fonte de volumoso foram significativamente menores quando comparadas com o grupo alimentado com volumoso $(\mathrm{P}<0,05)$ (Tab. 2). A população dos protozoários ciliados do rúmen pode variar entre $10^{4}$ e $10^{6}$ protozoários $/ \mathrm{mL}$ de conteúdo ruminal, dependendo do tipo de alimentação oferecida (Kamra, 2005).

Tabela 2.Concentrações médias de protozoários por mililitro de fluido ruminal de novilhos mestiços Nelore criados em pastagem lignificada ou confinados e alimentados sem volumoso

\begin{tabular}{ccccc}
\hline Categorias & Pequenos $^{1}$ & Médios $^{1}$ & Grandes $^{1}$ & Totais \\
\hline Com volumoso & $415.973,3 \mathrm{Aa}$ & $231.183,3 \mathrm{Aa}$ & $21.233,3 \mathrm{Ba}$ & $668.389,9 \mathrm{a}$ \\
Sem volumoso & $28.415,0 \mathrm{Ab}$ & $18.540,0 \mathrm{Bb}$ & $3.955,0 \mathrm{Cb}$ & $50.930,0 \mathrm{~b}$ \\
\hline
\end{tabular}

Médias seguidas de letras diferentes maiúsculas nas linhas e minúsculas nas colunas diferem entre si pelo teste t de Student $(\mathrm{P}<0,05)$.

${ }^{1}$ Pequeno (até $40 \times 60 \mu \mathrm{m}$ ), médio (até $100 \times 150 \mu \mathrm{m}$ ) e grande (maior do que $100 \times 150 \mu \mathrm{m}$ ).

Para todos os novilhos alimentados com a pastagem lignificada, observou-se coloração castanho e o pH médio foi 7,4 no líquido ruminal. Já para os animais confinados e alimentados somente com concentrado, observou-se fluido ruminal com coloração cinza leitosa. Dirksen (1993) relata que animais a pasto apresentam fluido ruminal com coloração verdeoliva ou castanho-esverdeada. Já o fluido do rúmen branco a cinza-leitoso sugere acidose ruminal (Dirksen, 1993). A redução do azul de metileno foi maior que seis minutos para os animais a pasto e menor que um minuto para $100 \%$ dos animais em confinamento. Dessa forma, os novilhos alimentados exclusivamente com concentrado apresentaram característica físico-química de acidose ruminal subclínica com pH médio de 5,07, justificando a menor concentração dos protozoários ruminais para esses novilhos, uma vez que, quando há acidose ruminal, ocorre morte desses ciliados (Kamra, 2005).

Nesses novilhos com acidose subclínica, a população de grandes protozoários, considerada mais sensível ao pH ácido (Dirksen, 1993), foi significativamente menor quando comparada a dos pequenos e médios ciliados do rúmen (Tab. 2). Três novilhos desse grupo que apresentaram $\mathrm{pH}$ ruminal inferior a 4 apresentaram-se defaunados. Segundo Jesus et al. (2012), a utilização de alto nível de concentrado na dieta reduz o número total de protozoários devido à queda no $\mathrm{pH}$ ruminal, uma vez que, em valores abaixo de 6,0, ocorre queda acentuada na concentração de protozoários totais.

No presente estudo, ambos os grupos apresentaram o limite mínimo da normalidade para a concentração desses ciliados. No grupo alimentado na pastagem, esse menor número poderia ser atribuído à baixa qualidade da dieta, e no grupo em confinamento, à redução significativa do $\mathrm{pH}$. Verificou-se correlação positiva $(\mathrm{P}<0,01)$ entre o $\mathrm{pH}$ e as médias de protozoários pequenos, médios, grandes e totais no fluido ruminal de novilhos Nelore avaliados (Tab. 3).

Tabela 3. Matriz de correlação de Pearson para as variáveis $\mathrm{pH}$, pequenos, médios, grandes e totais protozoários em novilhos Nelore

\begin{tabular}{lccccc}
\hline Variáveis & $\mathrm{pH}$ & Prot. pequenos & Prot. médios & Prot. grandes & Prot. totais \\
\hline $\mathrm{pH}$ & 1 & 0,6154 & 0,5331 & 0,6507 & 0,6227 \\
Prot. pequenos & & 1 & 0,7930 & 0,4796 & 0,9677 \\
Prot. médios & & & 1 & 0,5911 & 0,9205 \\
Prot. grandes & & & & 1 & 0,5679 \\
Prot. totais & & & & & 1 \\
\hline
\end{tabular}

Pesquisas apontam que protozoários ruminais apresentam-se em maior população quando a dieta é constituída de proporções mistas de volumoso/concentrado. Quanto maior a proporção de concentrado, menor será sua concentração, devido à acidificação do meio. Os protozoários são importantes no meio ruminal, pois fermentam carboidratos, usando amido e 
açúcares solúveis, evitando, assim, a rápida formação de ácido lático, o que estabiliza a fermentação ruminal e dificulta o abaixamento do pH (Jouany; Ushida, 1990; Ushida et al., 1990).

Resultados semelhantes foram descritos por Jóhannes et al. (2006), que observaram acentuada diminuição na população de protozoários com o incremento de amido em dietas para ruminantes. Entretanto, outros autores relataram aumento no número de protozoários à medida que se elevaram os níveis de concentrado adicionados às dietas (Martinele et al., 2008). De acordo com Franzolin e Dehority (2010), longos períodos de baixo $\mathrm{pH}$ ruminal, provavelmente, são mais prejudiciais para a sobrevivência dos protozoários ciliados no rúmen que outros fatores.

Dessa forma, protozoários ruminais são importantes na manutenção do $\mathrm{pH}$ do rúmen. $\mathrm{Na}$ ausência de protozoários ciliados no rúmen, o pH e as concentrações de nitrogênio amoniacal do fluido ruminal diminuíram, enquanto as concentrações de ácidos graxos voláteis totais, nitrogênio total e nitrogênio precipitável a ácido tricloroacético aumentaram (Santra e Karim, 2002).
Neste estudo, os bovinos alimentados em pastagem com elevado teor de fibra lignificada apresentaram média de grandes protozoários significativamente superiores àquelas de novilhos confinados e alimentados sem volumoso. Estudos têm apontado a importância desses protozoários na digestão de fibras. Enzimas produzidas por protozoários do rúmen constituem significante porção das enzimas hidrolíticas no rúmen (Agarwal et al., 1991). Em uma pesquisa, constatou-se que a menor atividade da carboximetilcelulase no rúmen de cordeiros defaunados contribuiu para a menor digestibilidade da celulose, indicando a relevância dos protozoários ciliados do rúmen na digestão das fibras (Santra e Karim, 2002).

Neste estudo, foram identificados 17 gêneros, com grande diversidade da população de ciliados no rúmen dos novilhos. Nesta pesquisa, para os animais alimentados em pastagens, os gêneros Dasytrichia, Charonina, Eudiplodinium, Entodinium, Diplodinium, Ostracodinium e Epidinium foram os de maior ocorrência. Entretanto, para aqueles alimentados sem volumoso, os gêneros Buetschilia, Isotricha, Eodinium, Polyplastron, Elytroplastron, Metadinium e Enoploplastron foram os mais frequentes (Tab.3).

Tabela 3. Distribuição dos gêneros de protozoários ruminais de novilhos zebuínos criados em pastagens lignificadas ou em confinamento sem volumosos

\begin{tabular}{|c|c|c|c|c|}
\hline \multirow{2}{*}{$\begin{array}{l}\text { Gêneros } \\
\text { Buetschilia spp. }\end{array}$} & \multicolumn{2}{|c|}{ Novilhos com volumoso } & \multicolumn{2}{|c|}{ Novilhos sem volumoso } \\
\hline & $483 b$ & $6,23 \%$ & $5550 \mathrm{a}$ & $29,38 \%$ \\
\hline Isotricha spp. & $733 b$ & $9,45 \%$ & $2170 \mathrm{a}$ & $11,48 \%$ \\
\hline Dasytricha spp. & $443 a$ & $5,71 \%$ & $730 b$ & $3,86 \%$ \\
\hline Charonina spp. & $1849 \mathrm{a}$ & $23,86 \%$ & $1410 b$ & $7,46 \%$ \\
\hline Entodinium spp. & $1303 \mathrm{a}$ & $16,81 \%$ & $2040 b$ & $10,79 \%$ \\
\hline Diplodinium spp. & $645 a$ & $8,32 \%$ & $660 \mathrm{~b}$ & $3,49 \%$ \\
\hline Eodinium spp. & $743 b$ & $9,58 \%$ & $2250 \mathrm{a}$ & $11,91 \%$ \\
\hline Eremoplastron spp. & $474 a$ & $6,11 \%$ & $1040 \mathrm{a}$ & $5,50 \%$ \\
\hline Eudiplodinium spp. & $261 \mathrm{a}$ & $3,36 \%$ & $380 b$ & $2,01 \%$ \\
\hline Diploplastron spp. & $232 \mathrm{a}$ & $2,99 \%$ & $410 \mathrm{~b}$ & $2,17 \%$ \\
\hline Polyplastron spp. & $94 \mathrm{~b}$ & $1,21 \%$ & $330 \mathrm{a}$ & $1,74 \%$ \\
\hline Ostracodinium spp. & $184 \mathrm{a}$ & $2,37 \%$ & $420 b$ & $2,22 \%$ \\
\hline Elytroplastron spp. & $35 b$ & $0,45 \%$ & $590 \mathrm{a}$ & $3,12 \%$ \\
\hline Metadinium spp. & $30 b$ & $0,38 \%$ & $240 \mathrm{a}$ & $1,27 \%$ \\
\hline Enoploplastron spp. & $45 b$ & $0,58 \%$ & $380 \mathrm{a}$ & $2,01 \%$ \\
\hline Ophyriscilex spp. & $28 \mathrm{a}$ & $0,36 \%$ & $50 \mathrm{a}$ & $0,26 \%$ \\
\hline Epidinium spp. & $167 \mathrm{a}$ & $2,15 \%$ & $240 \mathrm{~b}$ & $1,27 \%$ \\
\hline Total & 7749 & $100 \%$ & 18890 & $100 \%$ \\
\hline
\end{tabular}

Médias seguidas de mesmas letras nas linhas não diferem entre si, comparadas estatisticamente pelo teste de quiquadrado $(\mathrm{P}>0,05)$. 
Essas diferenças observadas para as populações de protozoários ruminais neste estudo corroboram a pesquisa de Williams (1986), que reporta que a dieta é um dos fatores mais importantes para a concentração e a distribuição de protozoários existentes no rúmen.

Outro estudo constatou a diversidade entre as comunidades de protozoários ruminais de novilhos alimentados com feno ou alimentados com silagem de grãos. De acordo com métodos moleculares e microscópicos, o gênero Entodinium foi mais abundante em bovinos alimentados com silagem de grãos. Por outro lado, a diversidade de ciliados ruminais foi maior para aqueles alimentados com feno, demonstrando maior estabilidade do ambiente ruminal (Tymensen et al., 2012).

Silva et al. (2014) também constataram a influência da dieta sobre a população de protozoários, ocorrendo queda na concentração de protozoários de acordo com o aumento do período de seca,quando a pastagem disponível para a alimentação era de menor qualidade. Para vacas leiterias, a inclusão de torta de macaúba no concentrado reduziu significativamente a concentração de protozoários ciliados no líquido ruminal (Santos et al., 2015).

Grandes protozoários da família Ophyroscolecidae, como Epidinium spp., Polyplastron spp. e Eudiplodinium spp., apresentaram níveis elevados de endoglucanase e xilanase (Takenaka et al., 2004). No presente estudo, as populações de Epidinium spp. e Eudiplodinium spp. foram significativamente superiores para os novilhos em pastagem, corroborando a importância desses gêneros na digestão de fibras.

Contudo, estudos com animais defaunados mostraram que a exclusão desses eucariotos traria efeito benéfico sobre a taxa de crescimento e eficiência de conversão alimentar de animais em condições específicas de alimentação, como confinamentos (Bird et al., 1994;Santra et al., 1994). A defaunação poderia reduzir a produção de metano em $20-30 \%$ e aumentar a disponibilidade de energia metabolizável para os animais em cerca de $12 \%$ (Santra et al., 1994).A eliminação de protozoários ruminais (defaunação) tem aumentado as taxa de crescimento e o ganho médio diário (GMD) dos ruminantes (Newbold et al., 2015), especialmente quando o alimento é deficiente em proteína em relação ao conteúdo energético (Nguyenet al., 2016).

Os protozoários ruminais são produtores de hidrogênio $\left(\mathrm{H}_{2}\right)$ e sintetizam principalmente acetato e butirato em vez de propionato. Dessa forma, a defaunação deveria induzir maior proporção de propionato no ambiente ruminal, entretanto esse fenômeno nem sempre é observado (Hegarty et al., 2008). Contrariamente a esses benefícios da defaunação, alguns estudos concluíram que os protozoários representam componente essencial do ecossistema microbiano no rúmen e que a sua exclusão tem efeito negativo sobre a produtividade dos ruminantes e a digestibilidade da fibra e da celulose (Santra e Karim, 2000; Santra e Karim, 2002).

A defaunação não alterou a produção diária de metano entérico 10-25 semanas após o tratamento (Bird et al., 2008) e em cordeiros sem protozoários do nascimento ou do desmame (Hegarty et al., 2008). A ausência de protozoários ruminais, portanto, nem sempre reduz as emissões de $\mathrm{CH}_{4}$ (Morgavi et al., 2012; Kumar et al., 2013). Assim, o papel dos protozoários do rúmen na moderação da concentração de $\mathrm{H}_{2}$ e da fermentação no rúmen não é consistente ou claramente compreendido para aos diferentes tipos de dietas ou categorias de ruminantes (Kumar et al., 2013; Nguyenet al., 2016).

As populações dos protozoários ruminais correlacionam-se positivamente com o pH do fluido ruminal de novilhos Nelore. Novilhos alimentados sem volumoso e com dieta com alto nível de inclusão de grãos apresentam menor população de protozoários ruminais do que aqueles criados em pastagem lignificada e apresentam perfis diferentes na distribuição de gêneros desses ciliados.

Palavras-chave: ciliados, microbiota ruminal, pecuária de corte, acidose ruminal, terminação 


\begin{abstract}
This study aimed to quantify and identify the profile of the rumen protozoa population of beef steers fed with or without roughage. Nellore crossbred steers raised in extensive system on lignified tropical pastures with mineral supplementation and steers confined for 60 days only receiving pelletized concentrate and whole corn kernels were evaluated. After slaughter, rumen fluid was collected and one $\mathrm{ml}$ aliquots were diluted in nine $\mathrm{ml}$ formaldehyde solution at 10\%. The counts of small, medium and large protozoa were held in Sedgewick Rafter chambers and identification of genus was possible after staining lugol and optical microscope with a $40 \mathrm{X}$ objective. The concentration of rumen protozoa positively correlated with pH ruminal. Cattle fed without roughage had significantly lower rumen protozoa population $(P<0.05)$. Animals fed roughage had higher occurrence of Dasytrichia genus, Charonina, Entodinum, Diplodinium, Ostracodinium and Epidinium while those fed without bulk, the Buetschilia, Isotricha, Eodinium, Polyplastron, Elyplastron, Metadinium and Enoploplastron were the most frequent genus.
\end{abstract}

Keywords: ciliates, rumen microorganisms, beef cattle, ruminal acidosis, termination

\section{REFERÊNCIAS}

ABRÃO, F.O.; DUARTE, E.R.; NIGRI, A.C. et al. Caracterização físico-química e microbiológica e população de fungos no conteúdo ruminal de novilhos de corte hígidos ou com acidose ruminal. Rev. Bras. Med. Vet., v.37, p.7-14, 2015.

AGARWAL, N.; KEWALRAMANI, N.; KAMRA, D.N. et al. Hydrolytic enzymes of buffalo rumen: comparison of cell free rumen fluid, bacterial and protozoal fractions. Buffalo J., v.7, p.203-207, 1991.

ALVARES, C.A.; STAPE, J.L.; SENTELHAS, P.C. et al. Köppen's climate classification map for Brazil. Meteorol. Z. v.22, p.711-728, 2014.

BIRD, S.H.; HEGARTY, R.S.; WOODGATE, $R$. Persistence of defaunation effects on digestion and methane production in ewes. Aust. J. Exp. Agric., v.48, p.152-155, 2008.

BIRD, S.H.; ROMULO, B.; LENG, R.A. Effects of lucerne supplementation and defaunation on feed intake, digestibility, $\mathrm{N}$ retention and productivity of sheep fed straw based diets. Anim. Feed Sci. Technol., v.45, p.119-129, 1994.

CARVALHO, G.G.P.; PIRES A.J.V. Organização dos tecidos de plantas forrageiras e suas implicações para os ruminantes. Arch. Zootec., v.57, p.13-28, 2008.

DEHORITY, B.A. Evaluation of subsampling and fixation procedures used for countig rumen protozoa. Appl. Environ. Microbiol.,v.48, p.182185,1984
DEHORITY, B.A. Laboratory manual for classification and morphology of rumen ciliate protozoa. Florida: CRC Press Inc., 1993. p.96.

DIRKSEN, G. Sistema digestivo. In: DIRKSEN,G.; GRUNDER,H.D.; STOBER, M. (Eds.). Rosenberger: exame clínico dos bovinos. Rio de Janeiro: Guanabara-Koogan, 1993. p.167169.

FRANZOLIN, D.; DEHORITY, B.A. The role of $\mathrm{pH}$ on the survival of rumen protozoa in steers. Rev. Bras. Zootec., v.39, p.2262-2267, 2010.

GOROCICA-BUENFIl, M.A.; LOERCH, S.C. Effect of cattle age, forage level, and corn processing on the diet digestibility and feedlot performance. J. Anim. Sci., v.83, p.705-714, 2005.

HEGARTY, R.S.; BIRD, S.H.; VANSELOW, B.A. et al. Effects of the absence of protozoa from birth or from weaning on the growth and methane production of lambs. Br. J. Nutr., v.100, p.1220-1227, 2008 .

JESUS, L.P.; CABRAL, L.S.; ESPINOSA, M.M. et al. Modelagem estatística para estimação da população de protozoários ruminais em função da relação volumoso: concentrado na dieta e da presença de aditivos. Rev. Bras. Saúde Prod. Anim., v.13, p.97-109, 2012.

JÓHANNES, S.; MURPHY, M.; UDÉN, P. Effect of the level of dry matter and protein and degradation rate of starch on in vitro ruminal fermentation. Anim. Feed Sci. Technol., v.130, p.191-203, 2006. 
JOUANY, J.P.; USHIDA, K. Protozoa and fibre digestion in the rumen. In: MOSHINO, S. et al. (Eds.).The rumen ecosystem. Tokyo: Japan Scientific Societies Press. Pringer-Verlag, 1990. p.139-150.

KAMRA, D.N. Rumen microbial ecosystem. Curr. Sci., v.89, p.125-135, 2005.

KUMAR, S.; DAGAR, S.S.; PUNIYA, A.K. et al. Changes in methane emission, rumen fermentation in response to diet and microbial interactions. Res. Vet. Sci., v.94, p.263-268, 2013.

MARTINELE, I.; SIQUEIRA-CASTRO, I.C.V.; D’AGOSTO, M. Protozoários ciliados no rúmen de bovinos alimentados com dietas de capimelefante e com dois níveis de concentrado. Rev. Bras. Saúde Prod. Anim., v.9, p.74-81, 2008.

MORGAVI, D.P.; MARTIN, C.; JOUANY, J.P. et al. Rumen protozoa and methanogenesis: not a simple cause-effect relationship. Br. J. Nutr., v.107, p.388-397, 2012.

NEWBOLD, C.J.; DE LA FUENTE, G.; BELANCHE, A. et al. The role of ciliate protozoa in the rumen. Front. Microbiol., v.6, p.1-14, 2015.

NGUYENA, S.H.; BREMNER, G.; CAMERONB, M. et al. Methane emissions, ruminal characteristics and nitrogen utilisation changes after refaunation of protozoa-free sheep. Small Ruminant Res., v.144, p.48-55, 2016.

SANTOS, A.C.R.; MAGALHÃES, D.Q.; AZEVEDO R.A. et al. Efeito da inclusão da torta de macaúba na população de protozoários do rúmen de vacas leiteiras. Arq. Bras. Med. Vet. Zootec., v.67, p.1653-1659, 2015.
SANTRA, A., KAMRA, D.N.; PATHAK, N.N. Effect-of-defamation on nutrientdigestibility and growth of Murrah buffalo (Bubalus bubalis) calves. Int. J. Anim. Sci., v.9 p.185-187, 1994.

SANTRA, A.; KARIM, S.A. Growth performance of faunated and defaunated Malpura weaner lambs. Anim. Feed Sci. Technol., v.86, p.251-260, 2000.

SANTRA, A.; KARIM, S.A. Influence of ciliate protozoa on biochemical changes and hydrolytic enzyme profile in the rumen ecosystem.J. App. Microbiol., v.92, p.801-811, 2002.

SILVA, K.L.; DUARTE, E.R.; FREITAS, C.E.S. et al. Protozoários ruminais de novilhos de corte criados em pastagem tropical durante o período seco. Ciên. Anim. Bras., v.15, p.259-265, 2014.

TAKENAKA, A.; TAJIMA, K.; MITSUMORI M.et al. Digestion by rumen ciliate protozoa. Microbiol. Environ., v.19, p.203-210, 2004.

TYMENSEN, L.; BARKLEY, C.; MCALLISTER, T.A. Relative diversity and community structure analysis of rumen protozoa according to T-RFLP and microscopic methods. J. Microbiol. Methods, v.88, p.1-6, 2012.

USHIDA, K.; KAYOULI, C.S.S.; JOUANY, J.P. Effect of defaunation on protein and fibre digestion in sheep fed on ammonia-treated strawbased diets with or without maize. Brit. J. Nutrit., v.64, p.765-775, 1990.

WILLIAMS, A.G. Rumen holotrich ciliate protozoa. Microbiol. Rev., v.50, p.25-49,1986.

ZERVOUDAKIS, J.T.; PAULINO, M.F.; DETMANN, E. Desempenho de novilhas mestiças e parâmetros ruminais em novilhos suplementados durante o período das águas. Rev. Bras. Zootec., v.31, p.1050-1058, 2002. 